\title{
Reactive transport modeling of uranium sequestration from field- scale injection of polyphosphate solutions in contaminated Hanford sediments
}

\author{
R.M. NELL* AND S. MEHTA
}

INTERA Inc., 3240 Richardson Rd., Suite 2, Richland, WA 99354, USA

(*correspondence: rnell@intera.com)

Persistent uranium groundwater plumes exist in the 300 Area of the Hanford Site located in the southeastern portion of Washington state, USA. Decades of uranium fuel fabrication generated waste that was discharged to surface ponds and trenches designed for infiltration. Enhanced attenuation was chosen to sequester residual uranium in the vadose zone over a $12,140 \mathrm{~m}^{2}$ (3 acre) area using polyphosphate solution treatment. The intent was to deliver polyphosphate solution at high concentrations to the vadose zone and top of the aquifer to bind the labile uranium mass via multiple mechanisms including: formation of calcium phosphate solids that co-precipitate and incorporate available uranium, sorption of aqueous uranium to calcium phosphate solids, and formation of uranium bearing minerals.

Coupled reactive-transport and variably saturated flow modeling is conducted using VS2DRTI software to develop an understanding of the subsurface reactions that lead to sequestration of uranium from injection of polyphosphate solutions. Reactive transport modeling was conducted to match 1-D column leaching experimental data to validate the implementation approach of using bulk kinetic rates for uranium in the pre- and post-treatment sediments. Field- and laboratory-data gathered from geochemical evaluations of pre- and post-treatment samples were used to develop a 3-D model to simulate treatment delivery at a representative injection well using radial coordinate system. Modeling was performed to understand geochemical changes and to predict thermodynamically favorable mineral precipitates in a complex system.

Results indicate that favorable conditions develop for multiple mechanisms of uranium sequestration including adsorption to reactive sorption sites, precipitation of uranium mineral phases, and formation of hydroxylapatite which can act as a coating around uranium minerals or co-precipitate available uranium in the porewater. 